RAE-IC, Revista de la Asociación Española de Investigación de la Comunicación vol. 9, núm. 17 (2022), 51-77 ISSN 2341-2690

Recibido el 26 de noviembre de 2021 DOI: https://doi.org/10.24137/raeic.9.17.3

Aceptado el 13 de enero de 2022

\title{
La imitación en televisión. Caracterizaciones de líderes políticos en EI intermedio, El hormiguero y Late motiv
}

\author{
Imitation on television. Characterizations of political leaders in EI \\ intermedio, El hormiguero and Late motiv
}

Gascón-Vera, Patricia

Universidad de Zaragoza (UNIZAR)

patriciagascon@unizar.es

Forma de citar este artículo:

Gascón-Vera, P. (2022). La imitación en televisión. Caracterizaciones de líderes políticos en El Intermedio, El hormiguero y Late motiv. RAE-IC, Revista de la Asociación Española de Investigación de la Comunicación, 9(17), 51-77.

https://doi.org/10.24137/raeic.9.17.3

\section{Resumen:}

El humor ha sido un componente inequívoco de la televisión y la política uno de sus resortes. En los últimos años, los humoristas Joaquín Reyes (El intermedio), Carlos Latre (El hormiguero) y Raúl Pérez (Late motiv) han imitado a políticos con motivo de las campañas electorales celebradas a nivel nacional y autonómico (2019 -2021). Desde un análisis de contenido de corte cualitativo, basado en categorías sobre humor e información periodística, se han conocido sus particularidades y el uso de la actualidad 
desde la parodia. Refrendado, además, con entrevistas en profundidad a dichos profesionales donde se ha constatado la importancia de una caracterización fiel, a través de un estilo propio desde el que tratan la información como segundo plano, pero sin dejar de lado aspectos informativos que conocen los humoristas y que plasma el equipo en el guion. Por su parte, los políticos son recurrentes en su abanico de personajes, pero no emplean un tratamiento específico. Los tics, la voz y la gestualidad se unen a la burla y las interpretaciones que forman parte del bagaje que cada humorista usa para llegar, desde este recurso humorístico recurrente en la historia televisiva, a una audiencia con un alto interés en la comunicación electoral.

Palabras clave: Imitación, parodia, humor, televisión, comunicación política, infoentretenimiento.

\begin{abstract}
:
Humour has been an unmistakable component of television and politics one of its springs. In recent years, the comedians Joaquín Reyes (El intermedio), Carlos Latre (EI hormiguero) and Raúl Pérez (Late motiv) have imitated politicians on the electoral campaigns held at the national and regional level (2019-2021). From a qualitative content analysis, based on categories on humour and journalistic information, its peculiarities, and its use of the present from the parody have been known. Also endorsed with in-depth interviews to these professionals where the importance of a faithful characterization has been verified, through their own style from which they treat information as a background, but without neglecting informative aspects that comedians know, and that incorporates by the script team. For their part, politicians are recurrent in their range of characters, but do not use a specific treatment. Tics, voice, and gestures join the mockery and interpretations that are part of their background that each comedian uses to reach, from this recurring humorous resource in television history, an audience with a high interest in electoral communication.
\end{abstract}

Keywords: Imitation, parody, humour, television, political communication, infotainment. 


\section{INTRODUCCIÓN}

En 2019 se celebraron dos elecciones generales en España, en los meses de abril y noviembre. Al mismo tiempo, tuvieron lugar comicios municipales, europeos y autonómicos con convocatorias anticipadas para la Asamblea de Madrid en mayo del 2021 y meses antes en Cataluña. Por todo ello, la actualidad electoral ha tomado una mayor relevancia en la agenda mediática. Tal y como indicaba el barómetro postelectoral del Centro de Investigaciones Sociológicas (CIS, 2019), en los primeros comicios el $35 \%$ de los entrevistados se interesó por la campaña, mientras que se duplicaron en las madrileñas (CIS, 2021).

De este modo, la información política en televisión prosigue una estela de interés que se extiende desde hace décadas, cuando Berrocal (2005, p. 3) advertía que, para la mayoría de los españoles, era una "fuente informativa y cultural" que cambió las decisiones políticas. Así pues, en 2019, fue el primer medio para informarse sobre las elecciones, más de un 40\% lo eligió primera opción, siendo este registro quince puntos superior en las autonómicas.

La comunicación política dispone de variados géneros televisivos (Pellisser y Pineda, 2014) para llegar a los espectadores. Las clásicas entrevistas o debates (Gutiérrez Lozano, 2020) son complementados con un nuevo abanico de fórmulas como encuentros en Todo es mentira (Cuatro, 2019-.), intervenciones en Buenismo Bien (SER) o contenidos en canales en Twitch.

Los políticos, cada día más, se atreven con el infohumor, fundamentalmente en campaña donde llegan a prestarse a compartir espacio con los humoristas, ante la repercusión social que pueden inferir en los ciudadanos. Sin embargo, a veces, surten críticas, como Donald Trump ante las últimas parodias de su campaña por el Saturday night live donde, con una postura proclive, registró un récord de audiencia. 
Imagen 1. Donald Trump en Saturday night live y Javier Lambán, presidente de Aragón, con el actor Rafa Blanca

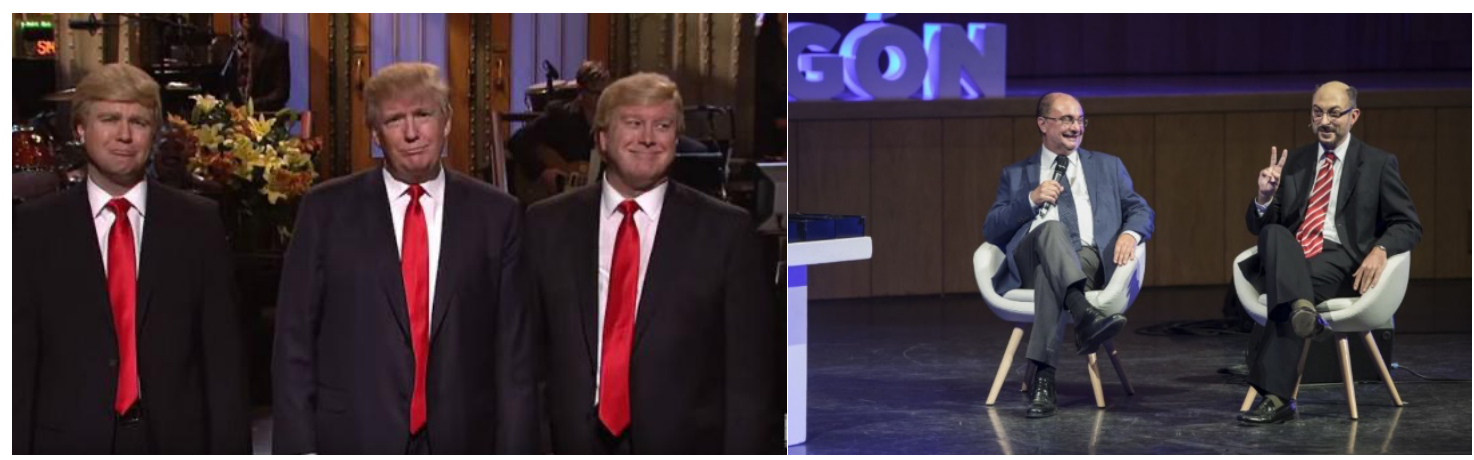

Fuentes: Elcomercio.pe y Radiohuesca.com

Desde esta realidad analizamos la parodia política en Late motiv, El hormiguero y El intermedio. El primero se ha emitido, hasta 2021, en la plataforma Movistar+ que ha marcado una nueva época para el humor en España (Balboa, 2018, p. 24) con una decena formatos, desde la llegada de Andreu Buenafuente y El Terrat (Gascón-Vera, 2020). Por su parte, los otros se mantienen desde 2006 en Antena 3 y La Sexta y generan sus picos de audiencia en las emisiones con vinculación política. Tal es así que el máximo de temporada 2020 para El intermedio fue la entrevista de Pablo Iglesias y, en 2021, El hormiguero ha superado los tres millones y medio de espectadores con Isabel Díaz Ayuso.

\section{MARCO TEÓRICO}

\subsection{HUMOR E INFORMACIÓN}

La información y el humor, como mezcla de contenidos televisivos, es un campo de investigación que se encuadra en la tendencia del infoentretenimiento (Krüger, 1988). El cual se origina en Estados Unidos y llega a la televisión española en la década de los noventa, debido a la privatización. Como cambio, generó nuevas estrategias narrativas y técnicas para presentar la actualidad (Ortells, 2012, p. 102). Además, en suma con la política, se enmarca en acepciones como politainment (Schultz, 2012), política pop (Mazzoleni y Sfardini, 2009) o la Tercera Edad de la Comunicación Política de Blumler y Kavanagh (1999), desde la que Pérez et al. (2014, p. 46) sostienen que el discurso político se ha popularizado y que la frontera entre los contenidos se ha diluido. 
En esa hibridación de formatos, las imitaciones son una modalidad (Sangro y Salgado, 2008 , p. 35) que usa la actualidad como punto de partida donde "'clavan a conocidos personajes" y recrean, desde la distancia humorística, "situaciones conflictivas acontecidas a lo largo de la semana" (p. 176).

También, Pedrero (2008, pp. 33-34) incluye las imitaciones, gags o parodias y Gordillo apunta que el infoentertainment de imitaciones está marcado por personajes reales "con trascendencia informativa" (2009, p. 248). En otras palabras, la sátira comprende a personajes públicos, de la cultura popular y líderes políticos, sobre los que toman distancia (Valhondo, 2011, pp. 29-30).

Así, esta actividad humorística, que se ejecuta a raíz de un ejemplo, es un campo de investigación "inexplorado" y multiperspectivista, como se desprende de la clasificación de Fernández (2018, p. 293) quien la sitúa en los inicios del medio, pero con "gran presencia" en la actualidad. Más allá, en conjunción con la política y la television, Martín y Berrocal (2017) analizan los pioneros del infoentretenimiento, Méndez (2014) en los noventa y su traslación en formatos como Carpio (2008) o Gascón-Vera (2019). De forma internacional, Hakola (2019) y Voth (2012) unen la materia electoral a las imitaciones políticas en Saturday night live que ejerce un papel fundamental en el cultivo de la sátira televisiva (Reincheld, 2006), en la parodia como creadora de realidades (Peifer, 2013) o, incluso, protagonizado los comentarios presidenciales de EE.UU (Compton, 2016).

Sobre sus razones de éxito, se extraen la saturación de informativos, el uso de la ironía, el descaro y la acidez, su frescura en la realización y su voluntad de transgredir para conseguir audiencia (García Avilés, 2004). Desde la infosátira, Valhondo (2007, p. 64) delimita su target joven, su emisión como contrapunto tras los informativos y su doble concepción. La de los detractores, donde se sitúa Berrocal (2005, p. 6), para quien los programas cómicos que parodian la política no contemplan que los ciudadanos comprendan mejor los acontecimientos, ni las decisiones de los representantes, ni son neutrales en periodo electoral. Un conocimiento sesgado que "no recibe un tratamiento riguroso y serio" y que entretiene desde la anécdota (Martín y Berrocal, 2017, p. 208). 
En el prisma contrario, Ulloa (2008, pp. 73 y 75 ) defiende que el periodismo que usa el humor "es eficaz, tanto en el mensaje como en su efecto" y que permite la evasión y el contrapoder. Al mismo tiempo que favorece el conocimiento a la población que no consume información convencional (Echeverría, 2020). Por su parte, desde la parodia política y la incidencia electoral, sobre Polònia (TV3), Ferré y Gayà ( 2010) determinan que puede influir en la actitud del telespectador hacia la persona real o reforzar su desencanto.

\subsection{IMITACIÓN Y TELEVISIÓN}

Las imitaciones juegan y rebajan la importancia que pueda tener el personaje (Casares, 2002, p. 179), el cual se construye al extraer los aspectos que los identifican (Echazarreta y Vinyals, 2012, p. 2), dado que los humoristas imitan el físico o el comportamiento de personajes reales con trascendencia informativa (Gordillo, 2009, p. 248). Como dispone Asa Berger (2017, p. 42), los imitadores, junto con su voz, pueden ridiculizar o exagerar a un personaje para facilitar su comparación e intentan replicar otras cualidades, como la teatralidad, el maquillaje o la semiótica comunicacional (Fernández, 2018, p. 294).

Posiciones y características ante un contenido que, históricamente, ha tenido una relación vinculante con la política. Carpio (2008, p. 2) testifica que son "viejos protagonistas" en los medios de comunicación y que, bajo estas fórmulas, consiguen una mayor audiencia y elevarse frente a su competencia. Un modo que había sido testado en Estados Unidos desde los late nights y que en Europa apareció con los Monty Python en 1968, en la BBC; al unísono de los muñecos de látex Spitting Image que parodiaban a dirigentes mundiales y personajes de actualidad con los que abarcaban temas heterogéneos (Herrero, 2018, p. 206). Una esencia que se plasmó en España con Los muñegotes o Los guguqús, ambos en TVE, y, después, con Los guiñoles de Canal+ que parodiaban a protagonistas político-sociales con su imitación física, desde un análisis informativo (Jaén, 2008, p. 297).

Para Antona (2017, p. 31), el entretenimiento es un elemento fundamental y delimita como pionero a Gran parada (1959-1964) o Aplauso que, desde 1978, ofrecía actuaciones musicales y humorísticas (Guerrero, 2010, p. 56). Sin obviar a Tip y Coll "Ios 
primeros en hacer gags televisivos" (Buenafuente, 2011, p. 172) y noticias políticas en Todo es posible en Domingo (1974).

A posteriori, llegaron las cadenas privadas ávidas audiencia con una programación de variedades cuyo objetivo era la diversión sin reflexión (Méndez, 2004, pp. 158-159). Telecinco con Tutti frutti o VIP (1990-1992), Humor cinco estrellas (1991-1993) Entre platos anda el juego (1990-1993), Genio y Figura (Antena 3, 1994) y Noche de fiesta (TVE, 1999-2004) se interesaron por Gila, Pepe Viyuela y parejas humorísticas como El Dúo sacapuntas, Martes y Trece, Cruz y Raya y Los Morancos. Los que ya intervenían en el Un, dos, tres responda otra vez, el que les supuso un gran trampolín para protagonizar sus propios espacios donde, además de música y sketches, realizaban parodias de famosos.

Asimismo, gracias a los excelentes registros en los audímetros, convirtieron su carisma en el ingrediente de galas y especiales de fin de año (Gascón-Vera, 2021), desde donde la parodia se convirtió en un género televisivo "recurrente" (Meléndez-Malavé, 2005, pp. 133-134) .

Como delimita Ortells (2009, p. 343), los políticos y sus personajes asumieron "un nuevo rol" al ser, desde entonces, una diana sobre la que realizar la sátira y la parodia. Y, por ello, se fueron fraguando formatos de humor como Este país necesita un repaso (Telecinco, 1993-1995) o, en Antena 3, Estamos todos locos (1994) y Al ataque (19921993), presentado por Alfonso Arús con Andreu Buenafuente o Fermí Fernández. Así lo recuerda Fernández (2018), ante otras propuestas con esta técnica como "máxima" como "Rambo" y "Chiquito de la Calzada" en Esta noche cruzamos el Mississippi o Parodia nacional. Así, la música ha sido un aliado de la parodia en Lluvia de Estrellas (1995-2007), Tu cara me suena (Antena 3, 2011-) o el reciente Me lo dices o me lo cantas (Telecinco, 2017), en los que la interpretación se convierte en un elemento más al servicio de la imitación. Al igual que sucedía con las caracterizaciones de Carlos Latre en Crónicas marcianas (Telecinco, 1997-2005) que, junto al Mississippi, fueron "excelentes" creadores de personajes sociales y latiguillos (Palacio, 2001, p. 169) como Bea la Becaria o La Pantoja de Puerto Rico, que impulsarían a Latre en Telecinco con Latrevisión (2004) y, posteriormente, Réplica (2008). 
En ese contexto, el auge de la imitación se plasma en el éxito de El informal (Telecinco, 1998-2002) junto con los doblajes y sketches (Gascón-Vera, 2019), con lo que consiguen superar los informativos de mayor audiencia (Valhondo, 2011, p. 36). Un hito tras el que llegaron las parodias del propio medio con Homo zapping en Antena 3 (2003-2007), luego en Neox, y La hora chanante (Paramount Comedy, 2001-2006) que saltó en abierto con Muchachada nuí (La 2, 2007-2010) y su sección "Celebrities". Una línea ascendente que se multiplicó con la llegada de Cuatro y La Sexta, desde la cual los formatos de este estilo adquirieron "un gran valor" (Salgado, 2010, p. 64).

La parrilla de La Sexta nació en 2006-2007 con A pelo, El club de Flo, Sabías a lo que venías o Los Irrepetibles; mientras, en Cuatro, ejercían parodias cotidianas Estas no son las noticias (2008) o Vaya tropa (2009-2010) que fue producido por Paukosa, responsable de Vaya semanita que, junto con Oregón TV y Polònia usan la parodia de políticos en las cadenas autonómicas (Gascón-Vera y Marta-Lazo, 2018, p. 201).

En esta senda, comediantes como José Mota han continuado protagonizando formatos en horarios de máxima audiencia (Diego y Grandío, 2011, p. 50) con "una completa sátira de la realidad" (Berrocal et al., 2014, pp. 98-99) hasta el presente. En 2020 Ese programa del que usted me habla, en La 2 , incorporaba imitaciones de Raúl Pérez y, en 2021, la cómica Cristina Gallego es, a diario, el alter ego de Isabel Díaz Ayuso, en El intermedio. Como novedad, Josep Ferré se caracteriza como los colaboradores de Sálvame, en una franja horaria no recurrente, pero con un prisma, los protagonistas del corazón, que utilizó Escobilla nacional (Antena 3, 2010).

\section{METOdOLOGÍA}

Por tanto, para abordar la imitación televisiva política como técnica humorística clásica presentamos los siguientes objetivos de carácter exploratorio, descriptivo y comparativo con los que responder a las preguntas de investigación:

- Analizar la imitación política en formatos de humor referentes en la actualidad. ¿Cómo han plasmado la política y sobre qué elementos de la información han versado? 
- Conocer cómo han sido ejecutadas las imitaciones políticas. ¿Cuáles son las técnicas, procesos y singularidades de cada uno de los imitadores?

- Descubrir las diferencias entre programas y su atención a las campañas electorales. ¿Las elecciones nacionales y autonómicas se tratan de la misma forma?

Para ello, se ha efectuado un análisis de contenido cualitativo de veinticuatro imitaciones de líderes políticos, emitidas entre 2019 y 2021, en tres formatos relevantes en materia de humor en el actual panorama mediático. Unido a las entrevistas en profundidad, de tipo sistemático, a los humoristas Joaquín Reyes, Carlos Latre y Raúl Pérez ${ }^{1}$, ya que, desde su experiencia se consiguen, al igual que Fernández (2018, p. 295), "ideas clave" al ser un objeto de estudio "vivo", además de conocer las circunstancias de su trabajo (Meléndez-Malavé, 2005, p. 22) para contrastar y contextualizar.

Tabla 1. Cuestionario empleado en las entrevistas

1. ¿Qué diferencia la imitación de un político a la de otro personaje? ¿todas las parodias políticas se trabajan por igual?

2. ¿Hay alguna característica en el formato para las imitaciones de políticos?

3. Las campañas electorales cambian el rumbo de las imitaciones en el formato o se sigue la estela marcada en el resto de temporada.

4. ¿Cómo se prepara a nivel humorístico la imitación de un político? ¿qué recursos son los más recurrentes y/o eficientes?

5. Qué evolución, características, similitudes o diferencias concibes en tu trabajo sobre líderes nacionales y autonómicos.

6. ¿Qué opiniones te han comentado los políticos sobre tus imitaciones?

7. ¿Cómo preparas la actualidad? ¿en el formato el nivel informativo-periodístico llega de la mano de los guionistas o de los redactores?

8. ¿Cómo estimas que se complementa el humor y la información?

9. Crees que los espectadores consiguen descifrar la actualidad o puede malinterpretarse.

Fuente: elaboración propia

${ }^{1}$ Raúl Pérez respondió el cuestionario vía email el 26 de julio de 2021, Carlos Latre envió su entrevista grabada el 13 de septiembre y con Joaquín Reyes se mantuvo una conversación telefónica de 45 minutos de duración el día 28 de octubre. 
Tabla 2. Listado de imitaciones codificadas

\begin{tabular}{|c|c|c|c|}
\hline \multirow{2}{*}{2019} & El intermedio & El hormiguero & Late motiv \\
& $\begin{array}{c}\text { Juanma Moreno Bonilla } \\
\text { Santiago Abascal } \\
\text { Isabel Díaz Ayuso } \\
\text { Quim Torra }\end{array}$ & Pedro Sánchez & $\begin{array}{c}\text { Manuela Carmena } \\
\text { Pablo Iglesias } \\
\text { Albert Rivera } \\
\text { Pablo Casado } \\
\text { Pedro Sánchez }\end{array}$ \\
\hline 2020 & $\begin{array}{c}\text { Rocío Monasterio } \\
\text { José María Aznar }\end{array}$ & Pedro Sánchez (III) & \\
\hline \multirow{2}{*}{2021} & $\begin{array}{c}\text { José Luis Martínez Almeida } \\
\text { Pedro Sánchez (repetición) }\end{array}$ & $\begin{array}{c}\text { José Luis Martínez Almeida (II) } \\
\text { Pablo Iglesias } \\
\text { Mariano Rajoy } \\
\text { Pedro Sánchez (II) }\end{array}$ & \\
\hline
\end{tabular}

Fuente: https://cutt.ly/5ORQaei

El modelo de análisis parte de la construcción televisiva de Pérez et al. (2014) y se complementa con los elementos de análisis sobre la comedia de Martín-Sánchez (2020), la escenografía (Gascón-Vera y Marta-Lazo, 2019), los movimientos de cámaras, planos, luz y color (Cortés-Selva, 2016).

Por su parte, como Fernández-Jiménez (2018), se distingue el estilo según la fidelidad al original, siendo espejo, cuando es preciso en fonética y gestualidad; base, cuando la imitación es una herramienta y se muestra la personalidad del imitador; su posibilidad mixta o múltiple cuando interpreta a un personaje a la par que otro. Posteriormente, se utilizan los valores noticiosos de Schulz (1982), el glosario de técnicas humorísticas de Berger (2017/1993, pp. 15-55) y los aspectos políticos de Gómez Morales (2020).

Tabla 3. Elementos de análisis para el estudio de las imitaciones

\begin{tabular}{|c|c|}
\hline \multicolumn{2}{|l|}{ 1. CARACTERÍSTICAS } \\
\hline 1.1 Caracterización & $\begin{array}{l}\text { Vestuario, maquillaje, voz/tono, atrezo, movimientos y } \\
\text { gestualidad }\end{array}$ \\
\hline 1.2 Emplazamiento & Plató: mesa o escenario, exteriores y/o croma \\
\hline 1.3 Visual & $\begin{array}{l}\text { Planos o detalles, diseño lumínico, color, rótulos y } \\
\text { postproducción }\end{array}$ \\
\hline 1.4 Sonido & Música y efectos \\
\hline 1.5 Estilo & Espejo, base, mixto o múltiple \\
\hline 1.6 Estructura & $\begin{array}{l}\text { Entrevista en directo, sección fija y/o colaboración con } \\
\text { invitados, interacción con el público }\end{array}$ \\
\hline \multicolumn{2}{|c|}{ 2. RECURSOS HUMORÍSTICOS } \\
\hline 2.1 Lenguaje & $\begin{array}{l}\text { Malentendido } \\
\text { Literalidad } \\
\text { Imitación voz } \\
\text { Juegos de palabras } \\
\text { Réplicas agudas }\end{array}$ \\
\hline
\end{tabular}




\begin{tabular}{|c|c|c|}
\hline & $\begin{array}{l}\text { Insultos } \\
\text { Infantilismo } \\
\text { Ironía }\end{array}$ & $\begin{array}{l}\text { Ridículo } \\
\text { Sarcasmo } \\
\text { Sátira } \\
\end{array}$ \\
\hline 2.2 Lógica & $\begin{array}{l}\text { Absurdo } \\
\text { Accidente } \\
\text { Analogía/ comparación } \\
\text { Catálogo-enumerar } \\
\text { Coincidencia } \\
\text { Decepción } \\
\end{array}$ & $\begin{array}{l}\text { Ignorancia } \\
\text { Errores } \\
\text { Repetición } \\
\text { Inversión } \\
\text { Rigidez } \\
\text { Tema / Variación }\end{array}$ \\
\hline 2.3 Identidad & $\begin{array}{l}\text { Antes y después } \\
\text { Burlesco } \\
\text { Caricatura } \\
\text { Excentricidad } \\
\text { Vergüenza } \\
\text { Exposición-denuncia } \\
\text { Grotesco }\end{array}$ & $\begin{array}{l}\text { Imitación } \\
\text { Interpretación } \\
\text { Mimetismo } \\
\text { Parodia } \\
\text { Escala } \\
\text { Estereotipo } \\
\text { Desenmascarar }\end{array}$ \\
\hline 2.4 Acción & $\begin{array}{l}\text { Persecución } \\
\text { Payasadas }\end{array}$ & $\begin{array}{l}\text { Velocidad } \\
\text { Hora }\end{array}$ \\
\hline \multicolumn{3}{|l|}{ 3. RECURSOS INFORMATIVOS } \\
\hline \multicolumn{3}{|l|}{ 3.1 Noticias de actualidad } \\
\hline \multicolumn{3}{|l|}{ 3.2 Tema principal } \\
\hline \multicolumn{3}{|l|}{ 3.3 Palabras clave } \\
\hline \multicolumn{3}{|l|}{ 4. ASPECTOS POLÍTICOS } \\
\hline 4.1 Representación del líder imitado & \multicolumn{2}{|c|}{ Neutral, cómica, favorable o desfavorable } \\
\hline $\begin{array}{l}\text { 4.2 Aspectos negativos y/o positivos } \\
\text { del imitado }\end{array}$ & \multicolumn{2}{|c|}{ Piropos, tacos, adjetivos físicos o psicológicos } \\
\hline $\begin{array}{l}4.3 \text { Nombra otros líderes políticos o } \\
\text { partidos }\end{array}$ & \multicolumn{2}{|c|}{ Comparación, sobrevaloración, mofa... } \\
\hline 4.4 Nombra campañas o elecciones & \multicolumn{2}{|c|}{ Pide el voto o no votar a la oposición } \\
\hline 4.5 Ámbito político & \multicolumn{2}{|c|}{$\begin{array}{l}\text { Ideología, corrupción, regulaciones de impacto social, } \\
\text { credibilidad institucional }\end{array}$} \\
\hline
\end{tabular}

Fuente: elaboración propia

\section{RESULTADOS}

En Late motiv las imitaciones de Pablo Iglesias, Pablo Casado, Albert Rivera y Pedro Sanchez se efectúan por las elecciones generales bajo la sección "Candidatos" y la de Manuela Carmela por la precampaña de Madrid, mientras que Almeida se imita como recurso a tenor de la actualidad, al igual que la totalidad de El intermedio que se estipulan dentro de la sección "Zanguangos" o "Zanguangos del futuro".

Por su parte, El hormiguero, además de esa razón, utiliza de forma reiterativa la figura de Sánchez. Así, Latre imita a políticos de forma sistemática, recuperando las imitaciones políticas en la sección fija "El teléfono escacharrado", donde interactúa con los invitados que deben repetir los fonemas que ejerce el humorista, dando por resultado una imitación múltiple, con un segundo, tercer e incluso siete parodiados. 
Por otro lado, en "Doble de acción" se visiona a Pablo Iglesias y Pedro Sánchez con un repaso más informativo, no solo como una caricatura, lo que completa, además, con la presencia en escena del propio imitado. Martínez Almeida se mimetizó con el humor, realizó chistes, interpretó una canción y utilizó el sarcasmo: “Me estoy jugando la reelección".

Imagen 2. Fotogramas de las secciones en los formatos de estudio

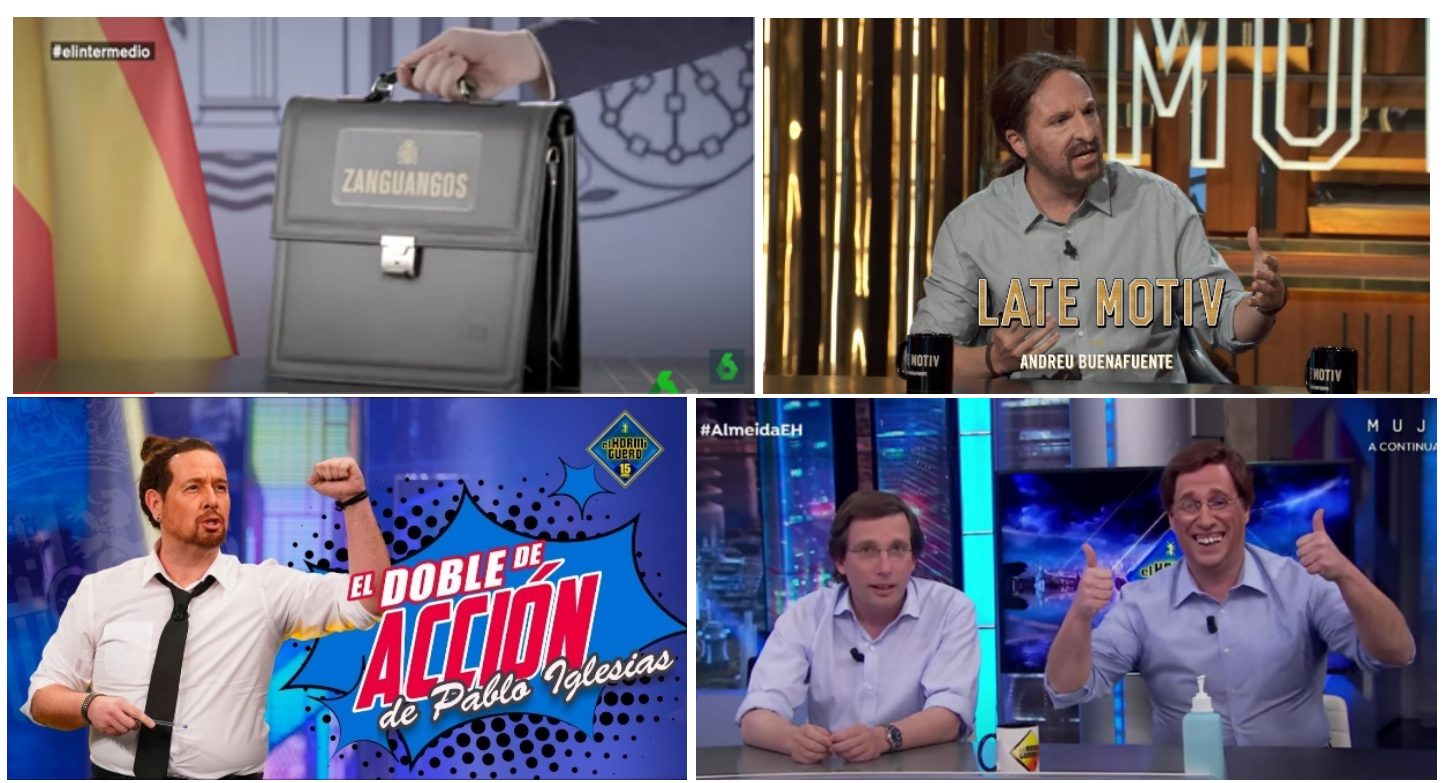

Fuentes: Lasexta.com, YouTube El hormiguero, Antena3.com y YouTube Late motiv

En todos los casos se efectúa una caracterización completa con pelucas y prótesis, siendo más realista y con rasgos más exagerados en El intermedio. La gestualidad y movimientos son trabajados con gran representatividad y exactitud en los otros dos formatos, siendo la parodia de Sánchez en El hormiguero la que más utiliza los abrazos, mientras Reyes continúa con los movimientos y palabras originarias de Muchachada nuí como "estoy chetao" o "gracejo".

Su representación fiel también se consigue desde el vestuario, a excepción de la sobre parodia que ejercita Latre a Almeida al ir vestido en sus pies como Olaf de Frozen. En este sentido, el atrezo ayuda a identificar los remakes de estos políticos, estimulando la significación y reflejando ridiculización u agresividad. 
Imagen 3. Listado de atrezos utilizados en los visionados

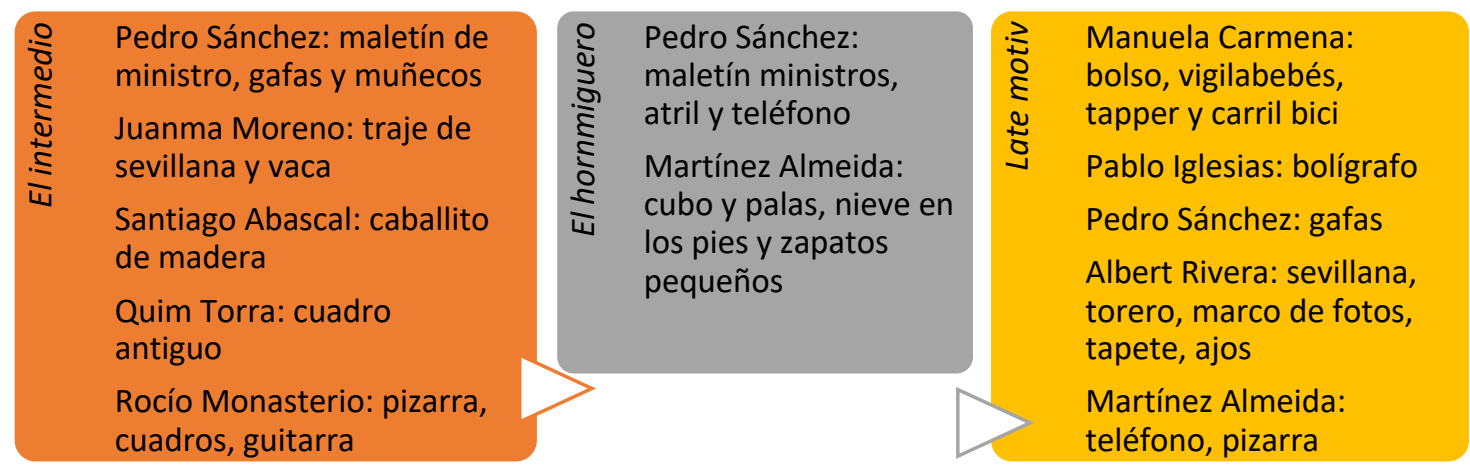

Fuente: elaboración propia

Sobre los estilos, Pérez y Latre consuman imitaciones espejo por voz, complexión y comportamiento y, por el contrario, Reyes ha generado una base propia. Efectúa todas las figuras con el mismo acento manchego desde su presentación, en una parodia donde son ridiculizados y se busca la risa entre los receptores a modo de burla. Otro resultado destacable es una doble parodia de Pérez, mitad en cada parte de su cuerpo, y que, por unos segundos, genera un tercero: "Por un lado soy Casado, por el otro Albert Rivera.... $Y$ de frente soy Pajares".

El tono está al servicio de la imitación. Pérez genera uno bajo para Rivera, la S para Casado y ascendente para Sánchez. Igualmente, Latre expone un tono bajo a Iglesias, por cómo ha cambiado su rol al formar parte del Gobierno.

Al mismo tiempo, su emplazamiento es una diferencia reseñable. Late motiv realiza una entrevista con el presentador en la mesa del programa y, fuera de elecciones, utilizan el escenario para el sketch, al igual que en El hormiguero. Sin embargo, El intermedio, al ser grabado, utiliza exteriores, generalmente parques; recreaciones de los despachos o sus trabajos como ruedas de prensa que se completan con el croma-Key. Todos los visionados suelen apostar por planos medios, contraplanos y generales para presentar al personaje, momento donde, al igual que en la despedida, la música suele tener un peso determinante, al igual que en su desarrollo. Una herramienta de identificación a través del uso reiterativo de himnos de los partidos y desde el guion, con un pasodoble para Abascal o Frozen para Almeida. 
Raúl Pérez se presenta con la banda en directo y la música sirve para provocar la risa con una canción de Malú. Además, en Carmena canta y baila, con Iglesias protagoniza un rap y para Sánchez interpreta en calzoncillos. Por lo tanto, es habitual que finalice con una actuación. Un alto número de músicas actuales y su rápida escucha es la base de DJ Valdi en El hormiguero, donde Sánchez dispone referencias como la banda sonora de Pretty woman o Je T'aime para crear el clima de seducción, al igual que El intermedio.

Imagen 4. Efectos de vestuario y postproducción en Late motiv y El intermedio

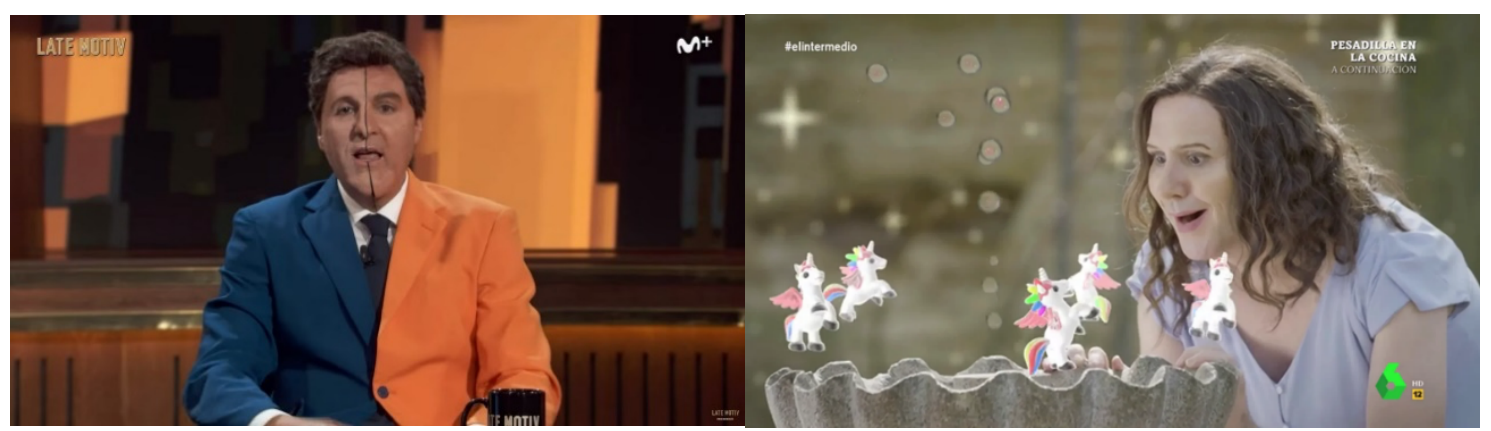

Fuentes: Movistar+ y Lasexta.com

Así, en La Sexta se atisba un mayor uso de efectos de sonido a favor del humor como pedos o relinchos que se unen a rótulos, imágenes trucadas, grafismos en movimiento y vídeos. No obstante, el equipo de Pablo Motos usa la pantalla posterior para proyectar fondos, vídeos o rótulos. También el público, participa de forma complementaria en el acto humorístico. Latre reparte como Iglesias fotos suyas y a Pérez le preguntan en la parodia de Almeida.

No hay diferencia entre imitar un político sobre otro personaje, según Joaquín Reyes, quien no cree en la equidistancia. "No puedes tratar a todos igual, hay una línea editorial que no puedes traicionar", reseña y asume el "peaje" de que haya gente que no le guste. Introduciendo al final de la entrevista que el humor está sujeto a la crítica, sobre todo, desde de las redes sociales, porque "la sociedad cada vez toma más partido" y está "más polarizada". Un momento, el actual, en el que, a su juicio, el humor está muy presente a razón de su alta demanda en formatos de sociedad o podcast y se distancia del humor de hace treinta años, marcado por la censura.

Autodefine su técnica como parodias que juegan a la abstracción, desde un contraste entre forma, con caracterizaciones muy sofisticadas que se identifican al primer golpe 
de vista, y el fondo, el acento manchego que sitúa al personaje ante un espejo deformado. "Al fin y al cabo estas jugando con la parodia que no es un homenaje, es una burla y tienes que desmontar al personaje", relata Reyes, quien estipula dos formas de trabajo. La primera, jugar a favor de la figura, subrayar sus características y cómo lo vemos y, la segunda, hacerlo al contrario de cómo lo imaginamos. "La gente es cómplice, no dejamos las cartas sobre la mesa y suele ser más divertido", explica.

\section{Imagen 5. Martínez Almeida y sus caracterizaciones}

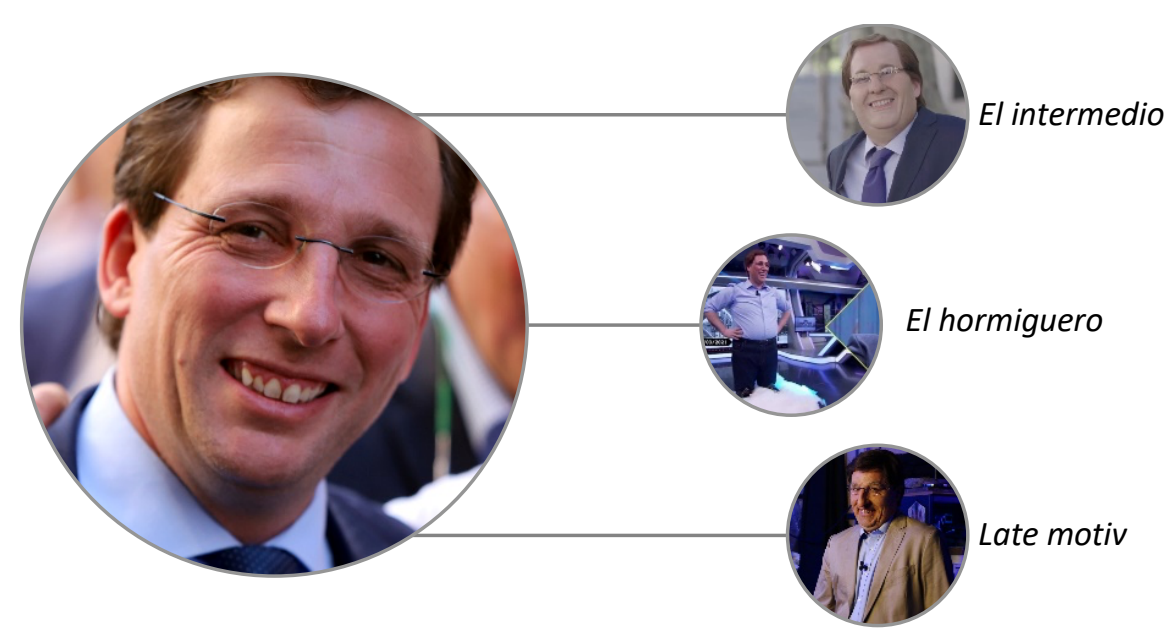

Fuentes: Wikimedia Commons, Lasexta.com y @raulperez_76

La máxima de Carlos Latre es fijar tics y miradas para "intentar captar el alma", al mismo tiempo que diferencia que los políticos son más planos por su tono de discurso. Pese a ello, ejerce la misma preparación, la observación de su físico, movimientos, forma de hablar, voz y gestos, sin olvidar la caracterización: “En Sánchez o Ábalos, cuando te pareces muchísimo, se afianza el personaje y te aporta seguridad". Misma reflexión que Reyes, quien sobredimensiona el maquillaje al relatar que si no pueden lograr un buen resultado desechan al personaje.

Es muy muy eficaz, porque no voy a tener la herramienta de la voz (...) Lo vivo de forma diferente, las prótesis me ayudan a crear comedia y cuando me veo caracterizado es mágico, soy otra persona y lo utilizo a nivel físico. (Joaquín Reyes) 
Asimismo, relata cómo fueron pioneros en este tipo de caracterizaciones, ya que antes atendían a una forma "mucho más primitiva". Una influencia que aterriza en el trabajo de Pérez con un diseño de maquillaje "más caricaturesco, menos naturalista" y sobre el que subraya su trabajo vocal y su creación "permanente" de nuevos personajes.

El propio, Raúl Pérez destaca la coordinación entre redacción y guion, siendo este último el pilar que sostiene sus imitaciones, junto con la caracterización, el estilismo y el decorado. Componentes que, como considera, generan "una magia increíble" desde la que es capaz de desaparecer como humorista y convertirse en los personajes. En su opinión, la parodia política tiene "un contexto común", pero cada personaje "tiene su forma de hablar, tics, temas preferidos y tabús" y desvela que prepara cada figura sobre sus peculiaridades. De los políticos subraya su gran exposición "voluntaria o involuntaria" al protagonizar las noticias, por lo que considera una ventaja que Late motiv sea diario, al tener la actualidad "muy presente". Por otro lado, evoca al desgaste físico que sufren y soltura comunicativa que ganan estos lideres. De igual manera, para Latre al principio son mucho más hieráticos y después adquieren confianza.

Sobre las campaña electorales, para Pérez son "un valor añadido a la hora de captar la forma de ser del personaje" y Latre señala que "son más enérgicas" y les aportan más tics y frases para agarrar al personaje. Pérez continúa reflejando que "existe una mirada constante hacia el gobierno desde las autonomías y viceversa" y apunta que lo nacional y lo autonómico coexisten a un nivel de importancia "muy parejo", tal y como reflejan las palabras clave. 
Imagen 6. Elementos del discurso informativo en las parodias analizadas

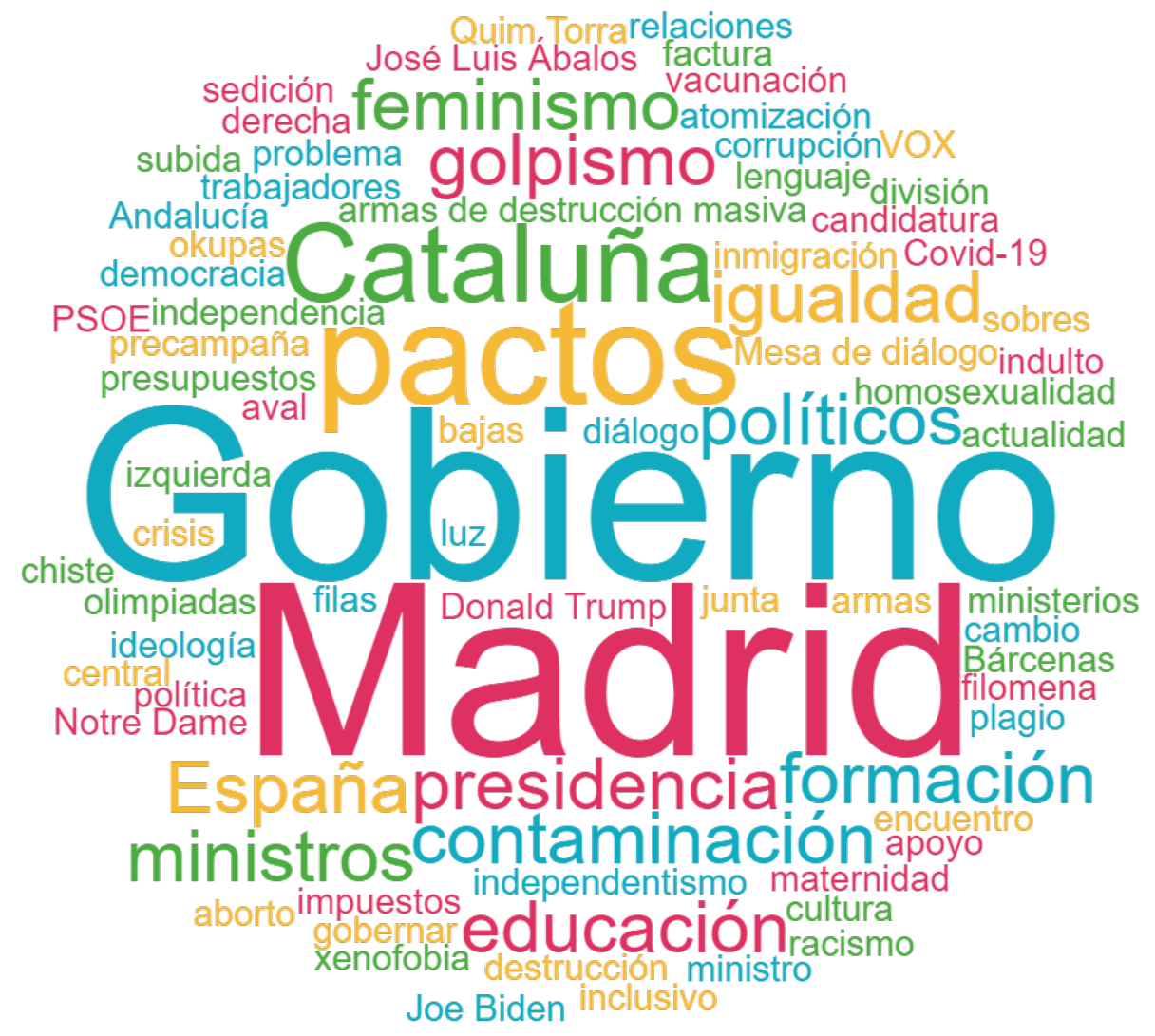

Fuente: elaboración propia

Para Latre, la imitación requiere estar "muy al hilo de la actualidad" y para conocer el discurso de los políticos sigue las noticias en informativos y periódicos. Asimismo, considera que "el humor es necesario para reflejar de forma diferente lo que pasa en el día a día", un punto de vista "más ligero" ante una realidad "muy dura" y le inscribe cualidades como exponer, al igual que Polònia donde trabajó, a la clase política de una forma más cercana e incluso humanizar al político, sobre todo, cuando participan en las imitaciones. Todo, porque, si se consideran las palabras de Reyes, la actualidad política suscita "un gran interés", aunque deja los efectos en el público a la espera de conocer estudios en la materia. Latre sí cree que las imitaciones informan y quizá "deforman un poco la realidad", desde el prisma del humor.

En su opinión, la información política "es compleja de asimilar en bruto y tiene muchas capas". Una estela que continúa Pérez, para quien el espectador descifra la actualidad, sin obviar problemas como la sobreinformación y la gran cantidad de fake news que, 
como determina, motivan a seleccionar "sitios de referencia". "El humor puede ayudar precisamente a interpretar la actualidad, aportando otra visión y creando puntos de encuentro", se reconforta. A continuación, los tres coinciden en que reciben buenas críticas. "Hay risas en el Gobierno y buen rollo al respecto de mis imitaciones", confirma Latre y se refiere al humor blanco y familiar que le caracteriza porque "no hace falta herir a nadie para hacer reír". Pérez, por su parte, actuó en una gala suscitando las risas de Iglesias, Rivera y la felicitación de Miguel Ángel Revilla, que hace extensible al ex ministro Salvador Illa.

También, Reyes narra su encuentro privado con Soraya Sáenz de Santamaría, lo que denota, a su juicio, "inteligencia política". Misma idea que refleja de forma compiladora Latre, al indicar que "aceptar el humor es un signo clarísimo de inteligencia". Por ello, apuesta porque "las sociedades tienen que vivir con humor" $y$, sin ser una contradicción, lo adjetiva como "una de las cosas más serias". Una seriedad desde la que hacer reír con el uso mayoritario de alusiones, chistes y, en más de la mitad de los análisis, la ampulosidad e interpretaciones que se complementan con más de una decena de exageraciones, juegos de palabras, comparaciones, analogías y burlas.

Gráfico 1. Distribución de frecuencias de los elementos humorísticos de la muestra

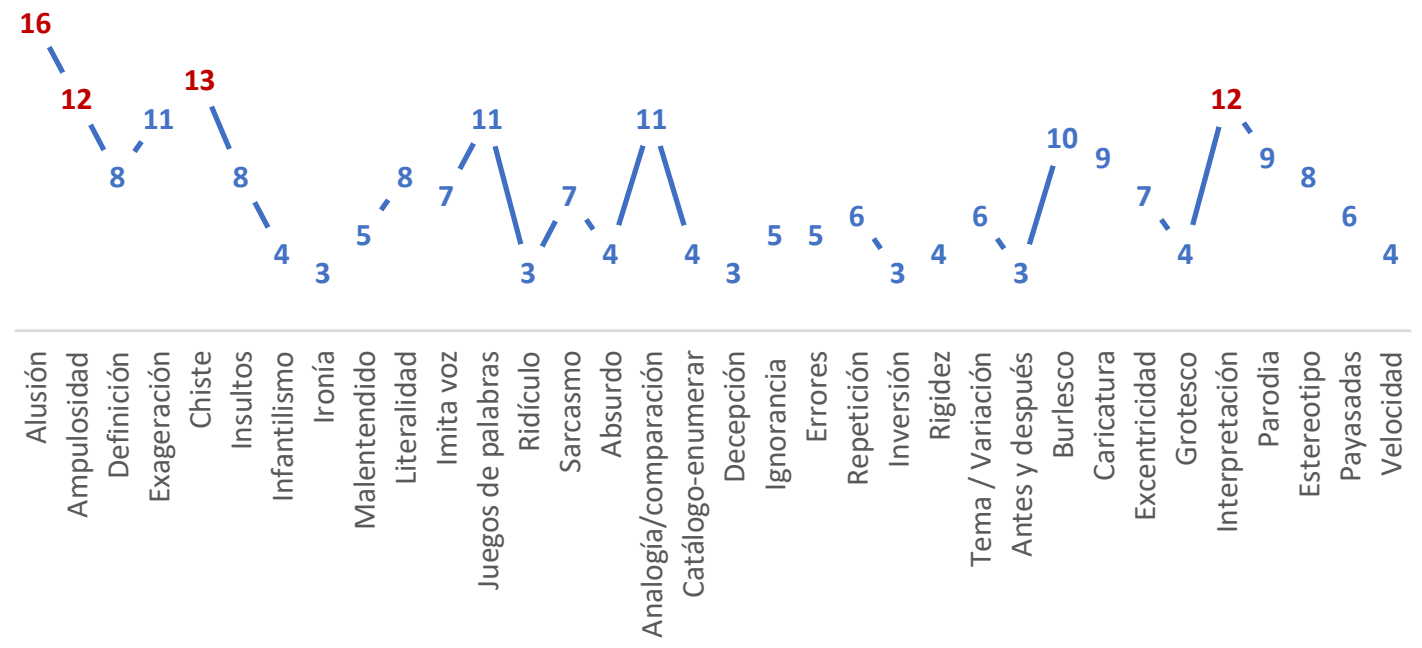

Fuente: elaboración propia

El intermedio actúa con un elemento no contemplado en el diseño, la incoherencia del personaje, por ejemplo a Quim Torra le gusta Melody como cantante. Reyes sostiene a los personajes desde extremos, gracias al sarcasmo unido a la decepción y la ignorancia. 
La excentricidad de una caricatura fuerte, desde la que articula una burla continua con el uso destacado de la exageración e infantilismos, con muñecos como público de Sánchez o un dibujo infantil firmado por Monasterio.

Gráfico 2. Composición de las parodias políticas de El intermedio

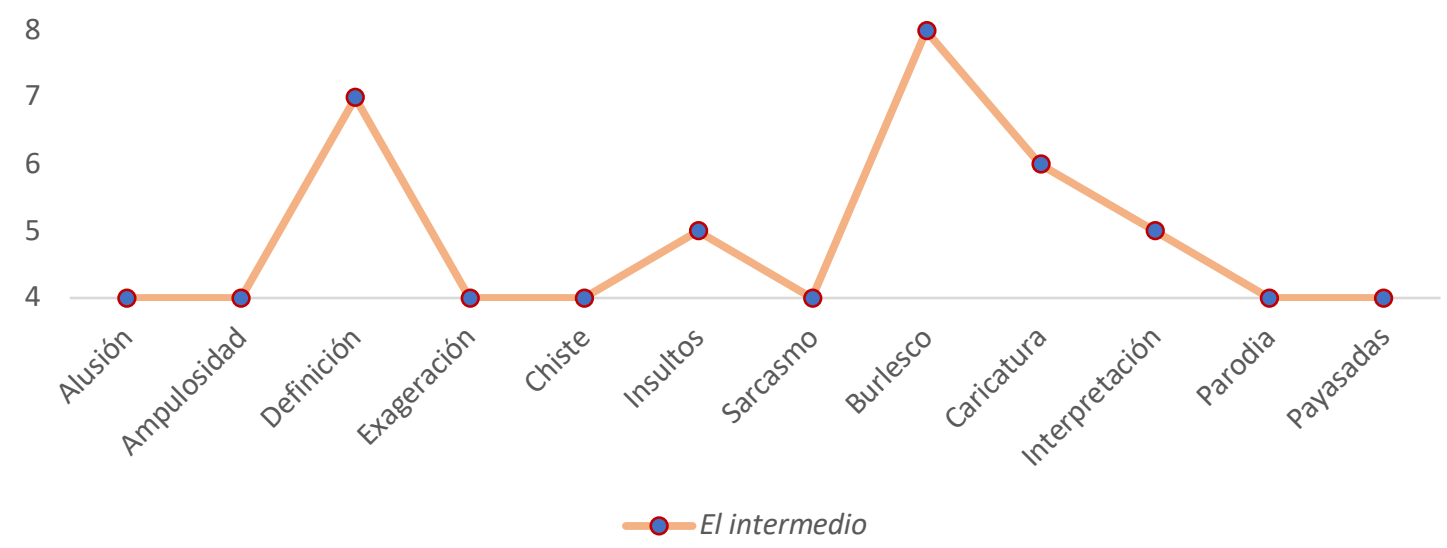

Fuente: elaboración propia

Asimismo, cada parodia se inicia con la propia definición del personaje: "Soy Isabel Natividad Díaz Ayuso, periodista, asesora, mujer, incluso, pero no feminaci, y sobre todo la orgullosísima presidenta de la Comunidad de Madrid". Un perfil sobre el que referirse a la situación política e informativa que se acompaña de piropos e insultos que glosan una mofa recurrente hacía dirigentes, compañeros de partido y adversarios en un guion enarbolado desde la retranca.

En el hormiguero la protagonista indiscutible es la doble imitación en el lenguaje a través de unos personajes dominados por el estereotipo de seductor y la ampulosidad de Sánchez: "No he venido a divertirme a El hormiguero, he venido a divertíos". La gráfica agrupa menos recursos por una menor repetición, pero se visionan usos variados de ironía "mi gobierno está falto de ministros", chistes o literalidad con el taburete y los sobres en Rajoy, así como casos únicos de acción, velocidad o payasadas. 
Gráfico 3. Composición de las parodias políticas de El hormiguero

8

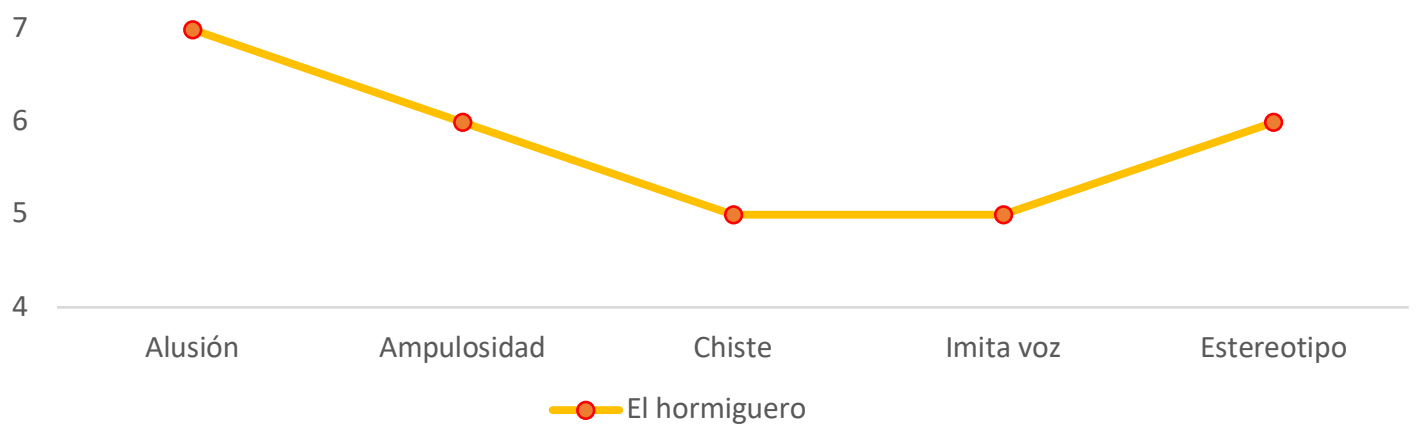

Fuente: elaboración propia

Pablo Motos sí realiza preguntas sobre la actualidad y la agenda del presidente del Gobierno: "qué tal ha ido este fin de semana con los ministros", "qué le va a pasar a Puigdemont" o "qué opina de la mesa de diálogo de Cataluña". Con lo que se denota que están ligados a la actualidad diaria, aunque sin relación efectiva con la campaña electoral, más allá de las entrevistas a candidatos en 2019.

En los espacios electorales de Late motiv se emiten los eslóganes, se deforman los parodiados desde la exageración, también desde chistes y juegos de palabras. Como particularidades, los insultos se ven en Iglesias, en Rivera el sarcasmo y las réplicas agudas en Casado. Se disponen analogías y comparaciones como la de Juegos de Tronos en Pablo Iglesias que deriva en una crítica velada a Carmena. Igualmente, los errores son criticados, así como las variaciones de temas. También desarrollan adjetivos físicos como la melena de Pablo Iglesias y Almeida se congratula de su gran nariz, junto con cuestiones psicológicas como la falta de verdad de Casado. Asimismo, se dan los dos únicos casos en los que se pide el voto, Carmena e Iglesias. Buenafuente unifica sus preguntas sobre feminismo, el punto fuerte de su campaña y les deja finalizar con un mensaje. Las escenas giran sobre los pactos de Gobierno y el independentismo de Cataluña. Por lo tanto, se hace un seguimiento de las elecciones desde las representaciones de los líderes, pero no a las noticias. 
Gráfico 4. Composición de las parodias políticas de Late motiv

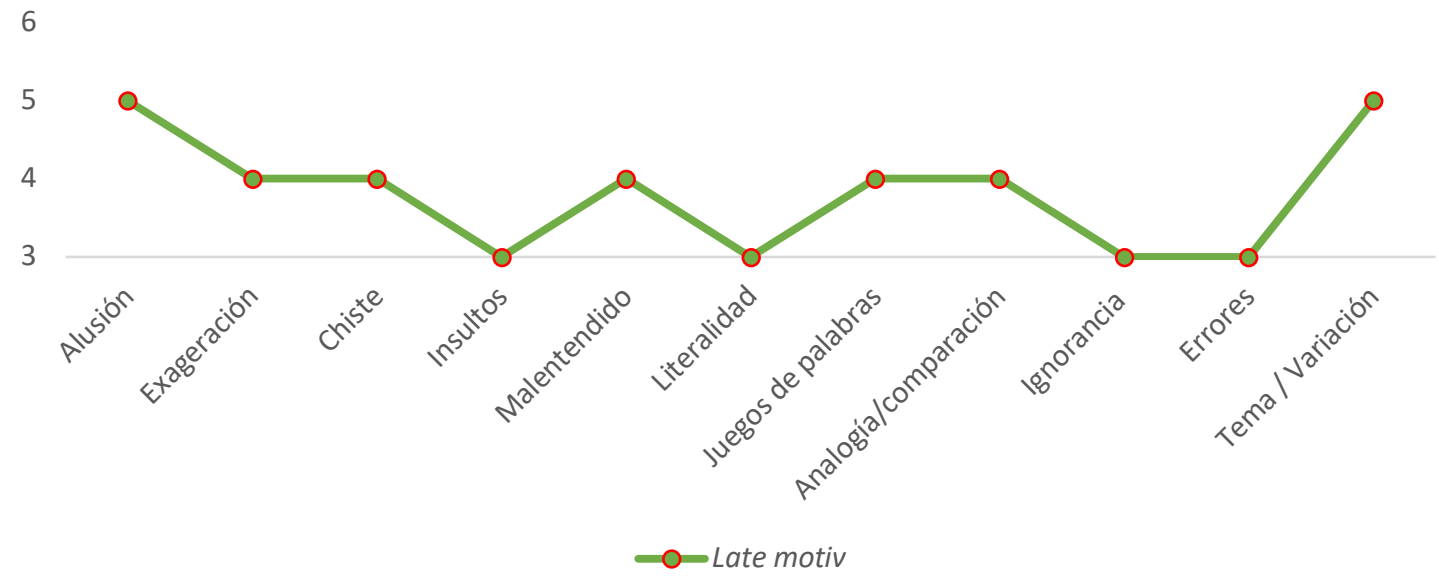

Fuente: elaboración propia

\section{CONCLUSIONES}

Pese a tratarse de formatos en continuo cambio, se han convenido las principales claves de sus imitaciones políticas en televisión al inicio de la segunda década del siglo XXI. Se comprueba que las parodias de infohumor no solo ocupan el ámbito nacional, si no que responden a la política centralista de Madrid. Sin perder de vista, fuera de la muestra, figuras internacionales como Boris Jonhson o Donal Trump que se convierten en nuevas oportunidades de investigación, junto con la evolución de este fenómeno.

En suma, el humor es un filtro desde el que se aborda la información y se imita; aquel que pretende, desde la risa, conectar y hacer disfrutar a un espectador al que interesa la política. Para ese cometido, se han programado a lo largo de las últimas décadas formatos de imitaciones de forma reiterativa, aunque no principal. Entre sus protagonistas, la parodia de políticos es una de las posibilidades de su guion, como se ha constatado en los formatos de análisis que la utilizan como entrevista, sección en directo o grabada.

Para ello, trabajan una puesta en escena con una caracterización completa, un vestuario y rostro fiel que les proporciona la magia necesaria; sobre todo en El intermedio, donde el maquillaje adquiere una importancia decisiva al no desarrollar aspectos como la voz, que es la protagonista en El hormiguero. El cual se basa en las capacidades de doblaje de Latre con una sección ad hoc donde trabaja los estereotipos de sus personajes recurrentes. 
Como se concluye, las parodias políticas se caracterizan por efectuar alusiones de forma directa, también desde la música y mediante los atrezos, junto con elementos clásicos como el chiste, las comparaciones o los juegos de palabras como generadores de ampulosidad y crítica sobre los líderes, para los que se decantan por un enfoque desfavorable desde la comicidad. Remakes donde los humoristas no emplean un tratamiento específico, pero sí destacan una postura editorial y su sobreexposición para conseguir humanizar al político con la burla irónica, el humor blanco o la fidelidad al original, respectivamente. Por lo tanto, queda resuelto que no existe una fórmula única, sino que se trata de hilos conductores sobre los que cada imitador genera un estilo propio del que se nutre cada formato.

Asimismo, se puede afirmar que las emisiones de humor estudiadas utilizan las imitaciones políticas para informar, más en El hormiguero que las condiciona a últimas noticias y a la agenda del presidente del Gobierno. No obstante, se desecha la idea de que las campañas motiven directamente esta técnica, salvo en Late motiv donde se pide el voto, aunque sí condicionan la elección de estos líderes por su representatividad mediática.

En definitiva, el humor para los imitadores es una forma de distorsionar la realidad, de acercar la política a los espectadores con una parodia, en suma con forma realista, pero en fondo diferenciada.

\section{AGRADECIMIENTOS}

Investigación realizada por personal investigador predoctoral en formación para el periodo 2018-2022, Departamento de Innovación, Investigación y Universidad del Gobierno de Aragón y cofinanciado con el Programa Operativo Fondo Social Europeo FSE 2014-2020, «Construyendo Europa desde Aragón».

Miembro del Instituto Universitario de Investigación Patrimonio y Humanidades y del Grupo de Investigación en Comunicación e Información Digital (GICID) de la Universidad de Zaragoza, reconocido como grupo de referencia, por el Gobierno de Aragón con el código S29_20R (Núm. 62 del Boletín Oficial de Aragón, de fecha 26/03/2020), dentro 
del área de Ciencias Sociales y financiado por el Fondo Social Europeo de Desarrollo Regional, FEDER “Construyendo Europa desde Aragón”.

\section{REFERENCIAS BIBLIOGRÁFICAS}

Antona, T. (2017). El entretenimiento como pilar de la programación televisiva durante el periodo 1958-75. Communication \& Society, 30(2), 31-45.

https://doi.org/10.15581/003.30.2.31-45

Balboa, M. (2018). Entre la risa y la ofensa Análisis de la censura como herramienta de control social y evaluación del estado del humor satírico en España. [Trabajo de Fin de Grado de, Universidad de Barcelona]. Recuperado de http://hdl.handle.net/2445/126689

Berger, A. A. (2017). An anatomy of humor. New York: Routledge.

Berrocal, S. (2005). La información política en televisión:¿apatía o interés entre los telespectadores?. Comunicar, (25). https://doi.org/10.3916/C25-2005-047

Berrocal, S., Redondo, M., Martín, V. y Campos, E. (2014). La presencia del infoentretenimiento en los canales generalistas de la TDT Española. Revista Latina de Comunicación Social, 69, 85-103. http://doi.org/10.4185/RLCS-2014-1002

Buenafuente, A. (Ed.), (2011a). Lo que vendría a ser la televisión en España según Buenafuente y el Terrat. Barcelona: Planeta.

Carpio, J. Á. (2008). El humor en los medios de comunicación: estudio de Los Guiñoles y sus efectos en las opiniones políticas. [Tesis doctoral, Universidad Pontificia de Salamanca]. https://doi.org/10.36576/summa.30168

Casares, J. (2002). Concepto del humor. Cuadernos de Información y Comunicación, 7, 169-187.

Centro de Investigaciones Sociológicas (CIS). (2019, diciembre). Barómetro postelectoral elecciones generales. Recuperado de http://datos.cis.es/pdf/Es3269marMT_A.pdf

Centro de Investigaciones Sociológicas (CIS). (2021, junio). Barómetro postelectoral elecciones autonómicas, Comunidad de Madrid. Recuperado de http://datos.cis.es/pdf/Es3328marMT_A.pdf

Compton, J. (2016). Live from DC: Saturday Night Live political parody references in presidential rhetoric. Comedy studies, 7(1), 62-78.

http://dx.doi.org/10.1080/2040610X.2016.1139808

RAE-IC, Revista de la Asociación Española de Investigación de la Comunicación vol. 9, núm. 17 (2022), 51-77 
Cortés-Selva, L. (2016). Fotografía y series de televisión. Metodología para el análisis del estilo visual televisivo. Index.comunicación, 6(2), 135-150.

Diego, P. y Grandío, M.a del M. (2011). Clasicismo e innovación en la producción nacional de comedia televisiva en España (2000-2010). Comunicación, 1(9), 49-66.

Echazarreta, C. y Vinyals, M. (2012). Tras las pistas de la parodia: análisis de contenido del humor y la parodia como posibles transmisores de estereotipos de género. En La Construcción de género en la ficción televisiva. Universitat de Girona.

Echeverría, M. (2020). Cuando el humor va en serio. Efectos del humor y la sátira política en actitudes ciudadanas. Estudos em Comunicação, 30, 1-19. Recuperado de http://ojs.labcom-ifp.ubi.pt/index.php/ec/article/view/557

Ferré, C. y Gayà, C. (2010). Infotainment y percepción ciudadana de la política: el caso de Polònia. Razón y Palabra, (72). Recuperado de https://cutt.ly/MOREOGq

Fernández, E. (2018). Las imitaciones humorísticas televisivas en España: propuesta de clasificación. Signa, (27), 293-322. https://doi.org/10.5944/signa.vol27.2018.19017

García Avilés, J. A. (2004). Distorsiones de la realidad en la neotelevisión. El pseudoperiodismo satírico y el periodismo de entretenimiento como subgéneros del info-show. En N. Mínguez y N. Villagra. (Eds.), La comunicación nuevos discursos y perspectivas, (pp. 37-45). Madrid: Edipo.

Gascón-Vera, P. (2019). 'El Informal', el doblaje y su programación en 'access prime ejes del éxito televisivo de un formato periodístico de humor. Index.comunicación, 9(3), 139-163. https://doi.org/10.33732/ixc/09/03Elinfo

Gascón-Vera, P. (2020). El infoentretenimiento en la televisión de pago, Movistar+ y el canal \#0. El uso transmedia de sus contenidos de humor. Ámbitos, 49, 177-196. http://dx.doi.org/10.12795/Ambitos.2020.i49.11

Gascón-Vera, P. (2021). La televisión en fin de año y los especiales de humor de José Mota. Imitaciones y parodias para relatar la actualidad y la COVID-19 desde la comedia. Revista ZER, 26(51). https://doi.org/10.1387/zer.22529

Gascón-Vera, P. y Marta-Lazo, C. (2019). Estructura y escenografía de los formatos periodísticos de humor del access prime time 2018-2019. Estudio comparativo entre Lo Siguiente, Ese programa del que usted me habla, El Hormiguero y El Intermedio. Textual \& Visual Media, (12). Recuperado de https://cutt.ly/RORENr8 Gascón-Vera, P y Marta-Lazo, C. (2018). Formatos al servicio del sketch: Oregón TV, Polònia y Vaya Semanita. El infoentretenimiento en las televisiones autonómicas 
españolas. En B. Puebla, E. del Campo y R. Gelado (Coords.), Sinergias digitales: hibridaciones entre información, ficción y entretenimiento, (pp. 195-216). Egregius.

Guerrero, E. (2010). El entretenimiento en la televisión española. Historia, industria y mercado. Barcelona: Planeta.

Gutiérrez Lozano, J. F. (2020). La progresiva extinción del debate y su aparente resurrección vía formatos de telerrealidad en la programación televisiva española (2004-2019). Estudios sobre el Mensaje Periodístico, 26(2), 611-621.

https://doi.org/10.5209/esmp.67819

Gómez Morales, B. (2020). Televisión crítica o industria de la risa: el caso de la comedia televisiva española (1990-2018). Signa, (29), 467-494.

https://doi.org/10.5944/signa.vol29.2020.23947

Gordillo, I. (2009). Manual de narrativa televisiva. Madrid: Síntesis.

Hakola, O. J. (2019). Imitaciones políticas en Saturday Night Live durante las elecciones presidenciales de Estados Unidos de 2016. En, N. Golubov. (Ed.), Tvficciones:

reflexiones críticas sobre televisión estadunidense, (pp. 241-271). Universidad Nacional Autónoma de México.

Herrero, M. (2018). Telemuñecos. Marionetas y muñegotes de la historia de la televisión. Madrid: Diábolo Ediciones.

Jaén, R. (2008). Los Guiñoles: 'Matarile, RIP, kaput' o 13 años riéndose de los poderosos (ustedes elijan). P. Sangro y P. Salgado. (Eds.), El entretenimiento en TV: guión y creación de formatos de humor en España, (pp. 296-297). Barcelona: Laertes.

Krüger, U. M. (1988). Infos- Infotainment- Entertainment? Media Perspektiven, 10.

Martín V. y Berrocal, S. (2017). Innovación y consolidación del «infoentretenimiento» político: una perspectiva histórica. Historia y Comunicación Social, 22(1), 207-219. http://dx.doi.org/10.5209/HICS.55908

Martín-Sánchez, D. (2020). La comedia de situación y su análisis textual: evolución de los elementos constructivos del formato. Ámbitos. (47), 238-266.

https://doi.org/10.12795/Ambitos.2020.i47.12

Mazzoleni, G. y Sfardini, A. (2009). Politica Pop. Bologna: II Mulino

Méndez, E. (2014). La parodia informativa como frivolización del discurso político. Círculo de Lingüística Aplicada a la Comunicación, 59, 61-91. 
Meléndez-Malavé, N. (2005). El humor gráfico en el diario El País durante la transición política española (1976-1978). (Tesis doctoral, Universidad de Málaga). Recuperado de http://hdl.handle.net/10630/5170

Reincheld, A. (2006). "Saturday Night Live" and Weekend Update: The Formative Years of Comedy News Dissemination. Journalism History, 31(4), 190-197.

https://doi.org/10.1080/00947679.2006.12062688

Sangro, P. y Salgado, A. (Eds.), El entretenimiento en TV: guión y creación de formatos de humor en España. Barcelona: Laertes.

Salgado, A. (2010). Actualidad, humor y entretenimiento en los programas de televisión: de la terminología a la realidad profesional. Trípodos, 27, 59-73.

Schultz, D. (2012). Politainment: The ten rules of contemporary politics: a citizens' guide to understanding campaigns and elections. Mykolo Romerio Universitetas.

Ulloa, C. (2008). Arma del contrapoder: Humor político y medios. Chasqui, (104), 72-77.

Ortells, S. (2009). La mercantilización de la información: la nueva era informativa en televisión. Revista Latina de Comunicación Social, 64, 341-353.

https://doi.org/10.4185/RLCS-64-2009-827-341-353

Ortells, S. (2012). Infoentretenimiento y periodismo político en televisión. En, A. Casero-Ripollés.(Ed.), Periodismo político en España: concepciones, tensiones y elecciones, (pp. 99-115). La Laguna: Sociedad Latina de Comunicación Social.

Palacio, M. (2001). Historia de la televisión en España. Barcelona: Gedisa.

Pedrero, L. M. (2008). Armas de seducción catódica: Los géneros de entretenimiento en la neo televisión contemporánea. En P. Sangro y A. Salgado. (Eds.), El entretenimiento en TV: Guion y creación de formatos de humor en España (pp. 33-54). Barcelona: Laertes.

Peifer, J. T. (2013). Palin, Saturday Night Live, and Framing: Examining the Dynamics of Political Parody. The Communication Review, 16(3), 155-177.

https://doi.org/10.1080/10714421.2013.807117

Pellisser, N. y Pineda, A. (2014). Información política televisiva y espectacularización: un análisis comparativo de programas informativos y de infoentretenimiento. Estudios sobre el Mensaje Periodístico, 20(2), 821-839.

http://dx.doi.org/10.5209/rev_ESMP.2014.v20.n2.47036 
Pérez, Ó., Oliva, M. y Pujadas, E. (2014). La construcción televisiva de la deliberación política. Análisis comparativo de programas informativos y de infotainment. Observatorio Journal, 8-2, 45-66.

Valhondo, J. L. (2007). Infosátira y democratización del espacio televisivo. Quaderns del CAC, 27, 63-71.

Valhondo, J. L. (2011). Sátira televisiva y democracia en España. La popularización de la información política a través de la sátira. Barcelona: UOC.

Voth, B. (2012). Saturday Night Live and presidential elections. En J. Baumgartner, Jonathan y S. Morris. (Eds.), Laughing matters (pp. 253-264). New York: Routledge. 